\title{
Promoting Safe Injection Practices, Substance Use Reduction, Hepatitis C Testing, and Overdose Prevention Among Syringe Service Program Clients Using a Computer-Tailored Intervention: Pilot Randomized Controlled Trial
}

Karli R Hochstatter ${ }^{1}$, MPH, PhD; Shawnika J Hull ${ }^{2}$, PhD; Ajay K Sethi ${ }^{3}$, MHS, PhD; Marguerite E Burns ${ }^{3}$, PhD; Marlon P Mundt ${ }^{4}$, MA, MS, PhD; Ryan P Westergaard ${ }^{3,5}$, MPH, PhD, MD

${ }^{1}$ Columbia University School of Social Work, New York, NY, United States

${ }^{2}$ Department of Prevention and Community Health, Milken Institute School of Public Health, The George Washington University, Washington DC, DC, United States

${ }^{3}$ Department of Population Health Sciences, University of Wisconsin School of Medicine and Public Health, Madison, WI, United States

${ }^{4}$ Department of Family Medicine and Community Health, University of Wisconsin School of Medicine and Public Health, Madison, WI, United States

${ }^{5}$ Department of Medicine, University of Wisconsin School of Medicine and Public Health, Madison, WI, United States

\section{Corresponding Author:}

Karli R Hochstatter, MPH, PhD

Columbia University School of Social Work

1255 Amsterdam Ave

New York, NY, 10027

United States

Phone: 12128512300

Email: krh2151@columbia.edu

\section{Abstract}

Background: Syringe service programs (SSPs) are safe, highly effective programs for promoting health among people who inject drugs. However, resource limitations prevent the delivery of a full package of prevention services to many clients in need. Computer-tailored interventions may represent a promising approach for providing prevention information to people who inject drugs in resource-constrained settings.

Objective: The aim of this paper is to assess the effect of a computer-tailored behavioral intervention, called Hep-Net, on safe injection practices, substance use reduction, overdose prevention, and hepatitis C virus (HCV) testing among SSP clients.

Methods: Using a social network-based recruitment strategy, we recruited clients of an established SSP in Wisconsin and peers from their social networks. Participants completed a computerized baseline survey and were then randomly assigned to receive the Hep-Net intervention. Components of the intervention included an overall risk synthesis, participants' selection of a behavioral goal, and an individualized risk reduction exercise. Individuals were followed up 3 months later to assess their behavior change. The effect of Hep-Net on receiving an HCV screening test, undergoing Narcan training, reducing the frequency of drug use, and sharing drug equipment was assessed. The individual's readiness to change each behavior was also examined.

Results: From 2014 to 2015, a total of 235 people who injected drugs enrolled into the Hep-Net study. Of these, 64.3\% (151/235) completed the follow-up survey 3-6 months postenrollment. Compared with the control group, individuals who received the Hep-Net intervention were more likely to undergo HCV testing (odds ratio [OR] 2.23, 95\% CI 1.05-4.74; $P=.04$ ) and receive Narcan training (OR 2.25, 95\% CI 0.83-6.06; $P=.11)$, and they shared drug equipment less frequently $(\mathrm{OR}$ 0.06, 95\% CI 0.55-0.65; $P<.001)$. Similarly, individuals who received the intervention were more likely to advance in their stage of readiness to change these 3 behaviors. However, intervention participants did not appear to reduce the frequency of drug use or increase their readiness to reduce drug use more than control participants, despite the fact that the majority of the intervention participants selected this as the primary goal to focus on after participation in the baseline survey.

Conclusions: Implementing computer-based risk reduction interventions in SSPs may reduce harms associated with the sharing of injection equipment and prevent overdose deaths; however, brief computerized interventions may not be robust enough to overcome the challenges associated with reducing and ceasing drug use when implemented in settings centered on the delivery of prevention services. 
Trial Registration: ClinicalTrials.gov NCT02474043; https://clinicaltrials.gov/ct2/show/NCT02474043

International Registered Report Identifier (IRRID): RR2-10.2196/resprot.4830

(J Med Internet Res 2020;22(9):e19703) doi: 10.2196/19703

\section{KEYWORDS}

hepatitis $\mathrm{C}$ virus; intravenous drug abuse; drug overdose; harm reduction; web-based intervention

\section{Introduction}

\section{Background}

The concurrent and overlapping epidemics of substance abuse, overdose, and hepatitis $\mathrm{C}$ virus (HCV) constitute a public health crisis. In the United States, an estimated 1.7 million people are affected by substance use disorders related to prescription opioids and 652,000 people are affected by heroin use disorders [1]. Moreover, approximately 70,237 Americans died from drug overdoses involving prescription opioids or illicit substances in 2017 alone, a four-fold increase since 1999 [2]. Through the sharing of needles and preparation equipment, injection drug use has fueled the spread of infectious diseases and now serves as the primary risk factor for $\mathrm{HCV}$ transmission in the United States [3]. From 2004 to 2014, acute HCV increased by $400 \%$ among Americans aged 18 to 29 years [4]. During this same period, there was an $817 \%$ increase in treatment admissions for injection of prescription opioids and a $603 \%$ increase in admissions for heroin injection [4].

These sharp increases in injection drug use and HCV incidence are concentrated in communities with traditionally poor access to prevention services, affecting rural and suburban residents in particular [5,6]. An epidemiologic investigation conducted to understand the factors associated with the tripling of $\mathrm{HCV}$ incidence between the periods of 2004 and 2008 and 2009 and 2010 in 6 contiguous rural counties of Wisconsin found that $94 \%$ of infected patients had shared hypodermic needles, drug preparation equipment, or drug snorting equipment [7]. Similar outbreaks of HCV among young persons who inject drugs have occurred across many other communities in the United States, including several Appalachian states, Massachusetts, Indiana, and New York State [6,8-11], and several other jurisdictions have been identified as potentially vulnerable communities to similar outbreaks [12].

Syringe service programs (SSPs) are safe, highly effective programs for promoting health among people who inject drugs. By providing access to sterile needles and other drug paraphernalia, these community-based programs have been shown to reduce the transmission of $\mathrm{HCV}$ and $\mathrm{HIV}$ among drug-using networks [13-18], without increasing the frequency of drug use [19-21]. In addition to distributing comprehensive prevention materials, SSPs often offer a range of services, including referral to substance use disorder treatment programs, education on safe injection practices, overdose prevention, and counseling and testing for HCV, HIV, and other sexually transmitted diseases. Despite the abundant documented benefits of SSPs, resource limitations prevent the delivery of a full package of prevention services to many in need [22-24].
Computer-tailored interventions (CTIs), in which the output of a persuasive technological system is adapted to the individual, are a low-cost strategy for delivering personalized health information that is specific to the unique psychosocial needs of each individual. Persuasive health technology is a growing field that combines medicine, computer science, and psychology to aid and motivate people to adopt behaviors that benefit them while avoiding the harmful ones and is used for both health promotion, prevention and disease management [25-27]. CTIs have become increasingly common for facilitating a wide range of healthy behaviors, including smoking cessation, diet and exercise, and mammography screening [28]. However, the use of CTIs to promote healthy behaviors among people who inject drugs, particularly in prevention-oriented and other community-based settings such as SSPs, remains to be less studied. CTIs may represent a promising approach for providing a personalized risk reduction plan for people who inject drugs in resource-constrained settings.

\section{Objectives}

Recognizing the growing demand for targeted, evidence-based interventions and the existing infrastructure of SSPs, a computer-tailored risk reduction intervention, called Hep-Net, was developed and implemented through a pilot randomized controlled trial (RCT) [29]. The objectives of this study are to evaluate whether incorporating a computerized behavioral intervention into existing prevention services at SSPs can lead to the adoption of healthier behaviors, including safer injection practices, substance use reduction, overdose prevention, and $\mathrm{HCV}$ testing.

\section{Methods}

\section{Study Population and Settings}

From 2014 to 2015, a total of 235 people who inject drugs enrolled in the Hep-Net study. Participants were either clients of an established SSP operating in 2 Wisconsin cities, Madison and Milwaukee, or peers recruited from the social networks of these clients. Eligibility criteria included being 18 years of age or older, having injected drugs in the past 30 days, and willingness to provide contact information for the 3-month follow-up.

To conduct outreach among high-risk populations of people who inject drugs and engage even those who do not regularly use prevention services, we used social network-based referrals to recruit the study sample. SSP clients were informed about the study during a routine needle-exchange encounter, invited to participate, screened for eligibility, and, if eligible, provided with the computerized baseline survey. After completing the baseline survey, participants were randomly assigned to receive 
the intervention, in which the computer immediately delivered the intervention content, or the control, in which the computer session was terminated after completion of the baseline survey. Upon completion of the baseline visit, study participants in both arms received referral coupons and were encouraged to refer eligible peers. Using the contact information provided at baseline, individuals were contacted 3 months later to complete the follow-up assessment. A protocol that describes in detail recruitment methods and intervention content and provides survey instruments and example content images of the Hep-Net intervention has been previously published [29].

\section{Risk Reduction Intervention}

The Hep-Net intervention aims to increase health-promoting behaviors and reduce risky drug use behaviors among people who inject drugs. Hep-Net targets 4 different behavioral domains: (1) undergoing regular HCV screening, (2) taking steps to prevent opioid overdose, (3) using clean works for every injection, and (4) reducing and ultimately ceasing injection drug use. Components of the intervention included an overall risk synthesis, participants' selection of a behavioral goal (from 1 to 4) and an individualized risk reduction exercise [29]. The risk synthesis had 2 components: first, positively framed feedback messages were delivered, highlighting healthy behaviors reported by participants that can reduce the risk of $\mathrm{HCV}$ transmission and opioid overdose, and second, tailored feedback was delivered regarding specific behaviors associated with increased risk reported by the participant. After selecting a behavioral goal, the participants were delivered a series of screens with feedback and educational content tailored to the individual's reported risk behaviors and their stage of readiness to change. Finally, during the interactive risk reduction exercise, the participants were asked to select 3 to 5 action steps from a list of 10 to 12 suggested steps that they were willing to do in the following 3 months.

Action steps considered during the individualized risk reduction exercise were tailored to the participant's readiness to change (as assessed at pretest) and are informed by the transtheoretical model (TTM), which conceptualizes behavior change as a continuum and argues that different processes of change are relevant to different stages of readiness [30]. According to the TTM, individuals who are not yet considering behavior change are in the precontemplation stage. In the contemplation stage, individuals may consider change but have not yet taken steps toward behavioral change. Contemplation is followed by preparation, action, and maintenance [31]. The Hep-Net intervention delivered feedback and risk reduction activities that were informed by the individual's stage of readiness, as described in the RCT's published protocol [29].

\section{Data Collection}

The baseline survey and the Hep-Net intervention were delivered from August 6, 2014, to April 16, 2015. Baseline information included demographics, drugs of choice, the duration of injection drug use, incarceration history, HCV status, the frequency of sharing needles, syringes and other works, naloxone (Narcan) training status, the frequency of drug use, and readiness to change each of the 4 targeted behaviors. Three-month follow-up surveys were conducted until August 18, 2015, and the same behaviors were assessed as the baseline questionnaire. All surveys were delivered on laptops and designed to last 20 to 30 $\min$.

In addition to the Hep-Net survey data, HCV testing data were collected and stored at SSP sites through the agency's standard protocol as well as in the Wisconsin Electronic Disease Surveillance System (WEDSS) in the Department of Health Services for those who tested HCV positive. These 2 additional data sources were used to track HCV testing for those who did and did not complete the follow-up survey, allowing us to measure the $\mathrm{HCV}$ testing uptake with greater validity. To assess HCV follow-up testing within 6 months of enrollment for all individuals enrolled in the study, we received participant-level data stored in the WEDSS through a secure, encrypted, and Health Insurance Portability and Accountability Act (HIPAA)-compliant data transfer protocol. Furthermore, archived testing records stored at the 2 SSP sites were manually searched to identify individuals who tested HCV negative. Study participants were matched to the WEDSS and SSP data by first and last name and date of birth. The variables collected from these sources include the date of HCV tests and test results.

\section{Main Outcomes}

We assessed 4 behavioral goals:

- Receive HCV follow-up testing: Individuals were considered tested for HCV at follow-up if they were not already aware of being $\mathrm{HCV}$ positive at the time of Hep-Net enrollment and if any of the following conditions were true: (1) self-reported at follow-up being tested for HCV since their first study visit, (2) underwent $\mathrm{HCV}$ testing at the time of the follow-up survey, (3) an archived record of an HCV test existed 6 months postenrollment at the SSP, or (4) any $\mathrm{HCV}$ test was reported to the WEDSS 6 months postenrollment.

- Get trained to administer Narcan: Individuals were considered trained to administer Narcan if they self-reported undergoing training for naloxone, or Narcan, in the follow-up survey. Those who were already trained at baseline were excluded from this analysis under the assumption that the knowledge and skills gained from such training last indefinitely.

- Reduce frequency of sharing drug equipment: To measure the frequency of sharing needles, syringes or other works, individuals were asked how often they shared (1) needles, (2) cottons or filters, and (3) cookers with another person when they used drugs in the past month. Responses were recorded using a slider-bar feature and ranged from $0 \%$ of the time they used drugs to $100 \%$. For this analysis, the frequency of sharing drug equipment corresponded to the highest percentage reported among these 3 pieces of equipment. When response data for one or more of these 3 questions were missing, it was assumed that the data were missing at random. These observations were excluded because we could not make an inference about why these data would be missing or hypothesize what these data would have been.

- Reduce the frequency of drug use: To measure the frequency of drug use, individuals were asked how often they used 
heroin; oxycodone, or OxyContin; methamphetamine (crystal or meth); and cocaine or crack in the past month. Four response categories were available, ranging from never to every day. For this analysis, the frequency of drug use corresponded to the highest frequency of use reported among these drug types and was collapsed into 3 categories: (1) never or less than once a week, (2) more than once a week but not every day, or (3) every day.

Understanding that behavior change often occurs through a series of stages as opposed to a single discrete event and that the Hep-Net intervention may not be powerful enough for some individuals to achieve full behavior change over the course of 3 months, we also assessed individuals' readiness to engage in these 4 health-promoting behaviors. At baseline and follow-up, individuals were presented with each of the 4 behavioral goals and asked to select their readiness to change each behavior. The 5 answer choices ranged from I am not even thinking about this goal to I have reached this goal, which corresponds with the 5 stages outlined by the transtheoretical model: precontemplation, contemplation, preparation, action, and maintenance. Owing to the low number of individuals observed in the contemplation and precontemplation stages, these stages have been combined into a single stage for this analysis.

\section{Statistical Analysis}

Descriptive statistics were calculated for the baseline variables of the entire study population. Characteristics of the intervention group were compared with those of the control group using Pearson chi-square (if expected cell frequencies are $>5$ ) or Fisher exact (if expected cell frequencies are $\leq 5$ ) tests for testing differences in categorical variables and the two-sample unpaired $t$ test (if normally distributed) or Wilcoxon rank-sum test (if not normally distributed) for continuous variables. Baseline characteristics were also examined to determine whether there were any characteristics that differed between those who returned for the follow-up survey and those who were lost, using the same statistical tests.

As the Hep-Net risk reduction intervention presented a menu of behavioral goals, providing the opportunity for behavior change beyond the behavior that was selected, analyses compared all intervention participants (as opposed to only those who selected the particular goal) with control participants. Binomial logistic regression was used to assess differences between intervention and control arms for binary outcomes: receiving $\mathrm{HCV}$ follow-up testing (yes or no) and undergoing Narcan training (yes or no). As the frequency of sharing drug equipment is a non-normally distributed outcome, we conducted Poisson regression to analyze the difference between the intervention and control arms in sharing equipment. Ordinal logistic regression was used to assess the difference in the frequency of drug use between the intervention and control arms. Ordinal logistic regression was also used to assess differences in intervention and control participants' readiness to change each behavior. All analyses were conducted using SAS version 9.4 (SAS Institute). Statistical significance was determined at $\alpha \leq .05$, two-sided.

\section{Results}

\section{Demographics}

During the enrollment period, 235 people who injected drugs provided consent and completed the baseline survey. Of these, 109 people were randomly assigned to the intervention group and 126 were assigned to the control arm. The baseline descriptive characteristics are displayed in Table 1. Among the 235 individuals, $180(76.6 \%)$ were male, $138(58.7 \%)$ were White, $211(89.8 \%)$ had at least a high school diploma or GED, $161(68.5 \%)$ were unemployed at the time of enrollment, and $172(73.2 \%)$ had an annual income of less than US \$11,500. A total of $44.7 \%(105 / 235)$ individuals used illicit substances every day at baseline. Heroin was the most common substance used in the past 30 days, with $87.2 \%(205 / 235)$ individuals using heroin, followed by cocaine or crack (147/235, 62.6\%), oxycodone or OxyContin (103/235, 43.8\%), and methamphetamine $(19 / 235,8.1 \%)$. At baseline, $71.1 \%(167 / 235)$ individuals self-reported ever being tested for $\mathrm{HCV}$ before Hep-Net study enrollment, of which $19.2 \%$ (32/235) reported testing $\mathrm{HCV}$ positive.

Of the 235 individuals who completed the baseline survey, 151 (64.3\%) completed the follow-up survey 3 to 6 months postenrollment. Individuals who were lost to follow-up were slightly less likely to have health insurance $(81.0 \%$ vs $90.0 \%$; $P=.05)$ and more likely to be homeless $(65.1 \%$ vs $47.0 \%$; $P=.008)$. This finding is expected, considering that homeless populations are often transient [32], which may lead to high study attrition and are less likely to have health insurance [33]. 
Table 1. Baseline demographic characteristics by intervention and control arm $(\mathrm{N}=235)$.

\begin{tabular}{|c|c|c|}
\hline \multirow[t]{2}{*}{ Characteristics } & \multicolumn{2}{|l|}{ Study $\operatorname{arm}^{\mathrm{a}}$} \\
\hline & Control $(n=126)$ & Intervention $(\mathrm{n}=109)$ \\
\hline \multicolumn{3}{|l|}{ Gender, n (\%) } \\
\hline Male & $92(73.0)$ & $88(80.7)$ \\
\hline Female & $34(27.0)$ & $21(19.3)$ \\
\hline \multicolumn{3}{|l|}{ Race, $\mathrm{n}(\%)$} \\
\hline White & $79(62.7)$ & $59(54.1)$ \\
\hline Black or African American & $32(25.4)$ & $34(31.2)$ \\
\hline Other or multiple & $15(11.9)$ & $16(14.7)$ \\
\hline Age (years), median (IQR) & $35(18)$ & $33(17)$ \\
\hline \multicolumn{3}{|l|}{ Education level, n (\%) } \\
\hline Less than high school & $17(13.5)$ & $7(6.4)$ \\
\hline GED $^{\mathrm{b}}, \mathrm{HSED}^{\mathrm{c}}$, or high school diploma & $61(48.4)$ & $50(45.9)$ \\
\hline At least some college & $48(38.1)$ & $52(47.7)$ \\
\hline \multicolumn{3}{|l|}{ Health insurance, $n(\%)$} \\
\hline No & $20(16.0)$ & $11(10.1)$ \\
\hline Yes & $105(84.0)$ & $98(89.9)$ \\
\hline \multicolumn{3}{|l|}{ Completed follow-up survey, n (\%) } \\
\hline No & $49(38.9)$ & $35(32.1)$ \\
\hline Yes & $77(61.1)$ & $74(67.9)$ \\
\hline \multicolumn{3}{|l|}{ Currently employed, n (\%) } \\
\hline No & $92(73.0)$ & $69(63.9)$ \\
\hline Yes & $34(27.0)$ & $39(36.1)$ \\
\hline \multicolumn{3}{|l|}{ Children at home, n (\%) } \\
\hline No & $100(79.4)$ & $88(80.7)$ \\
\hline Yes & $25(19.8)$ & $20(18.4)$ \\
\hline \multicolumn{3}{|l|}{ Income, US \$; n (\%) } \\
\hline None & $31(24.6)$ & $30(27.5)$ \\
\hline Less than 11,500 & $62(49.2)$ & $49(45.0)$ \\
\hline More than 11,500 & $28(22.2)$ & $30(27.5)$ \\
\hline \multicolumn{3}{|l|}{ Homeless in the past year, $n(\%)$} \\
\hline No & $58(46.0)$ & $51(46.8)$ \\
\hline Yes & $68(54.0)$ & $57(52.3)$ \\
\hline \multicolumn{3}{|l|}{ Incarcerated in the past year, $n(\%)$} \\
\hline No & $82(66.1)$ & $63(58.9)$ \\
\hline Yes & $42(33.9)$ & $44(41.1)$ \\
\hline \multicolumn{3}{|l|}{ Substance used in past 30 days, $n(\%)$} \\
\hline Heroin $^{\mathrm{d}}$ & $114(92.7)$ & $91(84.3)$ \\
\hline OxyContin or Oxycodone $^{\mathrm{d}}$ & $62(50.4)$ & $41(37.6)$ \\
\hline Methamphetamine & $11(8.7)$ & $8(7.3)$ \\
\hline Cocaine or crack & $79(62.7)$ & $68(62.4)$ \\
\hline Ever overdosed, n (\%) & & \\
\hline
\end{tabular}




\begin{tabular}{|c|c|c|}
\hline \multirow[t]{2}{*}{ Characteristics } & \multicolumn{2}{|l|}{ Study $\operatorname{arm}^{\mathrm{a}}$} \\
\hline & Control $(n=126)$ & Intervention $(\mathrm{n}=109)$ \\
\hline No & $75(60.5)$ & $70(64.2)$ \\
\hline Yes & $49(39.5)$ & $39(35.8)$ \\
\hline Percentage of time they share drug equipment ${ }^{\mathrm{e}}$, median (IQR) & $24.0(47)$ & $24.5(48)$ \\
\hline Has shared needles, cottons, filters, or cookers in the past 30 days, $\mathrm{n}(\%)$ & $99(88.4)$ & $87(87.9)$ \\
\hline Has shared needles in the past 30 days, $n(\%)$ & $78(70.9)$ & $67(69.1)$ \\
\hline Has shared cottons or filters in the past 30 days, $\mathrm{n}(\%)$ & $76(71.0)$ & $62(63.3)$ \\
\hline Has shared cookers in the past 30 days, $n(\%)$ & $86(81.9)$ & $72(77.4)$ \\
\hline \multicolumn{3}{|l|}{ Frequency of drug use in past 30 days, $n(\%)$} \\
\hline Less than daily & $67(53.2)$ & $63(57.8)$ \\
\hline Every day & $59(46.8)$ & $46(42.2)$ \\
\hline Years of injection drug use, median (IQR) & $5(13)$ & $7(13)$ \\
\hline \multicolumn{3}{|l|}{ Tested for $\mathrm{HCV}^{\mathbf{f}}$ before study enrollment, $\mathrm{n}(\%)$} \\
\hline No & $36(28.6)$ & $21(19.3)$ \\
\hline Yes & $85(67.5)$ & $82(75.2)$ \\
\hline Unsure & $5(4.0)$ & $6(5.5)$ \\
\hline \multicolumn{3}{|l|}{ Result of most recent $\mathrm{HCV}$ test, $\mathrm{n}(\%)$} \\
\hline Negative & $67(80.7)$ & $62(79.5)$ \\
\hline Positive & $16(19.3)$ & $16(20.5)$ \\
\hline \multicolumn{3}{|l|}{ Trained to administer Narcan at baseline, $n(\%)$} \\
\hline No & $77(61.1)$ & $62(56.9)$ \\
\hline Yes & $49(38.9)$ & $47(43.1)$ \\
\hline
\end{tabular}

${ }^{\mathrm{a}}$ Column percentages may not add up to 100 because the data are assumed to be missing at random.

${ }^{\mathrm{b}}$ GED: general educational development.

${ }^{\mathrm{c}}$ HSED: High School Equivalency Diploma.

${ }^{\mathrm{d}}$ Statistically significant at $\alpha<.05$ (unadjusted).

${ }^{\mathrm{e}}$ Includes needles, cottons or filters, and cookers.

${ }^{\mathrm{f}} \mathrm{HCV}$ : hepatitis $\mathrm{C}$ virus.

\section{Randomization Checks}

There were no significant differences in demographic variables (gender, race, age, education level, health insurance, employment, income, homelessness, incarceration history, or overdose history) between the intervention and control arms. Those randomized to the control group were significantly more likely to use heroin $(92.7 \%$ vs $84.3 \% ; P=.04)$ and OxyContin or Oxycodone $(50.4 \%$ vs $37.6 \% ; P=.05)$ in 30 days before baseline. As the use of these substances may affect the behavioral outcomes assessed in this study, we adjusted for heroin and OxyContin or Oxycodone use in all regression models. There were no significant differences at baseline between the intervention and control participants in the 4 behaviors that Hep-Net targets: the proportion screened for $\mathrm{HCV}$ or trained to administer Narcan, nor the frequency of sharing drug equipment or using drugs.

\section{Main Outcomes}

\section{Behavioral Goal 1: Receive HCV Follow-Up Testing}

Among the 235 study participants, 81 (34.5\%) individuals agreed to undergo a rapid $\mathrm{HCV}$ test at the time of study enrollment; none of the 32 individuals who self-reported already knowing to be $\mathrm{HCV}$ positive agreed to an $\mathrm{HCV}$ test at enrollment. Of the 81 individuals, $14(17 \%)$ tested reactive, and all 14 had a blood specimen collected and sent for confirmatory testing.

Of the 203 individuals who did not report testing positive for HCV before study enrollment, 38 (18.7\%) received HCV follow-up testing within 6 months of enrollment (Table 2). Individuals in the intervention arm were significantly more likely to undergo $\mathrm{HCV}$ follow-up testing than those in the control arm (23.7\% vs $14.6 \%$; OR 2.23 , 95\% CI $1.05-4.74$; $P=.04)$. This trend persisted at 12 months postenrollment, where $26.9 \%(25 / 93)$ of individuals in the intervention arm and $17.3 \%$ $(19 / 110)$ in the control arm received HCV follow-up testing. 
Table 2. Proportion who received Hepatitis $\mathrm{C}$ virus testing and underwent Narcan training, and the frequency of sharing drug equipment and using drugs at follow-up.

\begin{tabular}{|c|c|c|c|}
\hline Behavior & Control & Intervention & OR $(95 \% \mathrm{CI})^{\mathrm{a}}$ \\
\hline Received $\mathrm{HCV}^{\mathrm{b}}$ follow-up testing within 6 months $(\mathrm{n}=203)$, $\mathrm{n}(\%)$ & & & $2.23(1.05-4.74)^{\mathrm{c}}$ \\
\hline Yes & $16(14.5)$ & $22(24)$ & \\
\hline No & $94(85.5)$ & $71(76)$ & \\
\hline Trained to administer Narcan $(\mathrm{n}=91), \mathrm{n}(\%)$ & & & $2.25(0.83-6.06)$ \\
\hline Yes & $10(21)$ & $16(37)$ & \\
\hline No & $38(79)$ & $27(63)$ & \\
\hline Frequency of sharing drug equipment $(n=116)$ & & & $0.60(0.55-0.65)^{\mathrm{c}}$ \\
\hline Median percentage (IQR) & $5(1-47)$ & $2(1-24)$ & \\
\hline Frequency of drug use $(n=150), n(\%)$ & & & $0.90(0.49-1.65)$ \\
\hline Once a week or less & $25(33)$ & $22(30)$ & \\
\hline More than once a week but not every day & $30(39)$ & $28(38)$ & \\
\hline Every day & $21(28)$ & $24(32)$ & \\
\hline
\end{tabular}

${ }^{\mathrm{a}}$ Adjusted for heroin and OxyContin or Oxycodone use at baseline.

${ }^{\mathrm{b}} \mathrm{HCV}$ : Hepatitis $\mathrm{C}$ virus.

${ }^{\mathrm{c}}$ Statistical significance at $\alpha<.05$.

\section{Behavioral Goal 2: Gets Trained to Administer Narcan}

Among the 235 study participants, 96 (40.9\%) had already been trained to administer Narcan at baseline. Of the 151 individuals who participated in the follow-up survey, 60 were excluded from this analysis because they had been trained before Hep-Net enrollment $(n=59)$ or chose not to answer $(n=1)$. Of the remaining 91 individuals, $26(28.6 \%)$ received training between baseline and follow-up (Table 2). Individuals in the intervention arm were more likely to receive Narcan training than those in the control arm (37.2\% vs $20.8 \%$; OR $2.25,95 \%$ CI 0.83-6.06; $P=.11)$.

\section{Behavioral Goal 3: Reduce Frequency of Sharing Drug Equipment}

At baseline, 186/235 (79.1\%) reported sharing needles, cottons, filters, or cookers with another person in the 30 days before study enrollment: 145/235 (61.7\%) individuals reported sharing injection needles or syringes, $138 / 235(58.7 \%)$ shared cottons or filters, and 158/235 (67.2\%) shared cookers. Thus, the majority of participants shared more than one piece of equipment (98 individuals shared all the 3 pieces, 59 individuals shared 2 pieces, and 29 individuals shared 1 piece). A total of 25/235 $(10.6 \%)$ individuals reported never sharing any of these 3 pieces of equipment. The median percentage of time participants shared equipment at baseline was $24.0 \%$ (IQR 2.0-49.0).

At follow-up, the median percentage of time participants shared equipment dropped to $3.0 \%$ overall (IQR 1.0-28.0) among the 116 individuals who provided responses for all 3 pieces of equipment (Table 2). Individuals in the intervention group were significantly less likely to share drug equipment than individuals in the control group (control median, IQR 5, 1-47; intervention median, IQR 2, 1-24). Those in the intervention group shared drug equipment 0.60 times less than those in the control group (OR 0.60, 95\% CI 0.55-0.65; $P<.001$ ).

\section{Behavioral Goal 4: Reduce Frequency of Drug Use}

Overall, $44.7 \%$ (105/235) of individuals reported using drugs every day at baseline, compared with $30.0 \%$ (45/150) at follow-up. This reduction in the proportion of individuals using drugs every day was experienced by both intervention and control participants (Table 2), where $32.4 \%$ and $27.6 \%$ reported using every day, respectively (OR $0.90,95 \%$ CI $0.49-1.65$; $P=.72)$.

\section{Readiness to Change}

Table 3 shows the distribution of stages of readiness for change at baseline and at follow-up. This table also shows the odds ratios demonstrating the degree to which individuals in the intervention group advanced their stage of readiness in the direction of maintenance compared with the control group at follow-up. 
Table 3. Proportion of individuals in each stage of readiness for risk reduction behaviors at baseline and follow-up and odds ratios comparing the mean values of readiness to change between intervention and control groups at follow-up.

\begin{tabular}{|c|c|c|c|c|}
\hline Stage of readiness & $\mathrm{HCV}^{\mathrm{a}}$ testing intentions & Narcan training intentions & Intentions to use clean works & Intentions to reduce drug use \\
\hline \multicolumn{5}{|l|}{ Baseline (n=235), $\mathrm{n}(\%)$} \\
\hline \multicolumn{5}{|c|}{ Precontemplation and contemplation } \\
\hline Control group ${ }^{\mathrm{b}}$ & $25(19.8)$ & $34(27.0)$ & $15(11.9)$ & $25(19.8)$ \\
\hline Intervention group $^{c}$ & $19(17.4)$ & $24(22.0)$ & $9(8.3)$ & $19(17.4)$ \\
\hline Total & $44(18.7)$ & $58(24.7)$ & $24(10.2)$ & $44(18.7)$ \\
\hline \multicolumn{5}{|l|}{ Preparation } \\
\hline Control group & $31(24.6)$ & $28(22.2)$ & $13(10.3)$ & $32(25.4)$ \\
\hline Intervention group & $19(17.4)$ & $23(21.1)$ & $17(15.6)$ & $31(28.4)$ \\
\hline Total & $50(21.3)$ & $51(21.7)$ & $30(12.8)$ & $63(26.8)$ \\
\hline \multicolumn{5}{|l|}{ Action } \\
\hline Control group & $46(36.5)$ & $23(18.3)$ & $55(43.7)$ & $64(50.8)$ \\
\hline Intervention group & $45(41.3)$ & $20(18.4)$ & $44(40.4)$ & $54(49.5)$ \\
\hline Total & $91(38.8)$ & $43(18.3)$ & $99(42.1)$ & $118(50.2)$ \\
\hline \multicolumn{5}{|l|}{ Maintenance } \\
\hline Control group & $24(19.1)$ & $41(32.5)$ & $43(34.1)$ & $5(4.0)$ \\
\hline Intervention group & $26(23.9)$ & $42(38.5)$ & $39(35.8)$ & $5(4.6)$ \\
\hline Total & $50(21.3)$ & $83(35.3)$ & $82(34.9)$ & $10(4.3)$ \\
\hline \multicolumn{5}{|l|}{ Follow-up $(\mathrm{n}=151), \mathrm{n}(\%)$} \\
\hline \multicolumn{5}{|c|}{ Precontemplation and contemplation } \\
\hline Control group ${ }^{\mathrm{d}}$ & $12(16)$ & $17(22)$ & $4(5)$ & $7(9)$. \\
\hline Intervention group ${ }^{\mathrm{e}}$ & $9(12)$ & $11(15)$ & $3(4)$ & $9(12)$ \\
\hline Total & $21(13.9)$ & $28(18.5)$ & $7(4.6)$ & $16(10.6)$ \\
\hline \multicolumn{5}{|l|}{ Preparation } \\
\hline Control group & $4(5)$ & $10(13)$ & $3(4)$ & $11(14)$ \\
\hline Intervention group & $9(12)$ & $13(18)$ & $2(3)$ & $15(20)$ \\
\hline Total & $13(8.6)$ & $23(15.2)$ & $5(3.3)$ & $26(17.2)$ \\
\hline \multicolumn{5}{|l|}{ Action } \\
\hline Control group & $33(43)$ & $16(21)$ & $34(44)$ & $45(58)$ \\
\hline Intervention group & $24(32)$ & $13(18)$ & $23(31)$ & $41(55)$ \\
\hline Total & $57(37.7)$ & $29(19.2)$ & 57 (37.7) & $86(57.0)$ \\
\hline \multicolumn{5}{|l|}{ Maintenance } \\
\hline Control group & $28(36)$ & $34(44)$ & $36(47)$ & $14(18)$ \\
\hline Intervention group & $32(43)$ & $37(50)$ & $46(62)$ & $9(12)$ \\
\hline Total & $60(39.7)$ & $71(47.0)$ & $82(54.3)$ & $23(15.2)$ \\
\hline OR $(95 \% \mathrm{CI})^{\mathrm{f}, \mathrm{g}}$ & $1.23(0.67-2.24)$ & $1.28(0.70-2.34)$ & $1.92(0.99-3.71)$ & $0.67(0.36-1.27)$ \\
\hline
\end{tabular}

${ }^{\mathrm{a}} \mathrm{HCV}$ : hepatitis C virus.

$\mathrm{b}_{\mathrm{n}=126 .}$

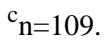

$\mathrm{d}_{\mathrm{n}=77 \text {. }}$.

$\mathrm{e}_{\mathrm{n}=74}$

${ }^{\mathrm{f}}$ The precontemplation and contemplation stages were combined into a single stage, resulting in a four-category dependent variable (stage of readiness) 
for each behavior. The probability of reaching the goal (maintenance) was modeled, with control participants being the reference group.

${ }^{g}$ Adjusted for heroin and OxyContin or Oxycodone use at baseline.

\section{Behavioral Goal 1: Receive HCV Follow-Up Testing}

Overall, the majority of individuals were in the preparation $21.3 \%$ (50/235), action $38.7 \%$ (91/235), or maintenance $21.3 \%$ (50/235) stage of readiness to undergo regular HCV screening. Of the 109 individuals in the intervention group, 3 (2.8\%) selected this goal to work on specifically over the next 3 months. At follow-up, a higher proportion of individuals reached the maintenance stage in both groups $(60 / 151,39.7 \%$ overall), with a slightly higher proportion in the intervention group (32/74, $43.2 \%)$ than in the control group $(28 / 77,36.4 \%)$. The odds of advancing through the stages of readiness toward the maintenance stage were $16 \%$ higher in the intervention arm than in the control arm (OR 1.23, 95\% CI 0.67-2.24; $P=.51)$

\section{Behavioral Goal 2: Get Trained to Administer Narcan}

At baseline, $21.7 \%(51 / 235)$ of individuals were in the preparation stage of readiness to undergo Narcan training, $18.3 \%$ $(43 / 235)$ were in the action stage, and $35.3 \%(83 / 235)$ were in the maintenance stage. Of the 109 individuals who received the intervention, $10(9.2 \%)$ chose this goal to work on specifically over the next 3 months. At follow-up, a higher proportion of individuals had reached the maintenance stage overall (71/151, $47.0 \%)$, with a slightly higher proportion in the intervention group $(37 / 74,50.0 \%)$ than in the control group $(34 / 77,44.2 \%)$. The odds of advancing through the stages of readiness toward the maintenance stage were $28 \%$ higher in the intervention arm than in the control arm (OR 1.28, 95\% CI 0.70-2.34; $P=.43$ ).

\section{Behavioral Goal 3: Reduce Frequency of Sharing Drug Equipment}

At baseline, the highest proportion of individuals were in the action stage $(99 / 235,42.1 \%)$ and the maintenance stage $(83 / 235$, $34.9 \%$ ) for using clean works every time they injected. Among the 109 intervention participants, 17 (15.6\%) selected this goal to work on over the next 3 months. The proportion of individuals reaching the maintenance stage at follow-up increased $(54.3 \%$ overall) among both groups but was higher among intervention participants (62.2\%) than among control participants (59/126, $46.8 \%$ ). The odds of advancing through the stages of readiness toward the maintenance stage were $80 \%$ higher in the intervention arm than in the control arm (OR 1.92, 95\% CI $0.99-3.71 ; P=.05)$.

\section{Behavioral Goal 4: Reduce Frequency of Drug Use}

At baseline, the highest proportion of people were in the preparation $(63 / 235,26.8 \%)$ and action $(118 / 235,50.2 \%)$ stages of readiness for the goal of reducing or ceasing drug use. In contrast to the other 3 behavioral goals, the least proportion of individuals were in the maintenance stage $(10 / 235,4.3 \%$ overall). The highest proportion of individuals in the intervention group $(72.5 \%)$ selected this goal to focus on over the next 3 months. Although the proportion of individuals reaching the maintenance stage at follow-up increased overall to $15.2 \%$ (23/151), individuals in the intervention group were less likely to advance along the readiness continuum in the direction of maintenance than those in the control group (OR 0.67, 95\% CI $0.36-1.27 ; P=.22)$.

\section{Discussion}

\section{Principal Findings}

The goal of this pilot RCT was to determine whether implementing a computerized risk reduction intervention into existing prevention services at SSPs can improve health-promoting behaviors among people who inject drugs. We found that individuals who received the Hep-Net intervention were significantly more likely to undergo testing for $\mathrm{HCV}$ and less likely to share drug equipment. Although not statistically significant, individuals in the intervention arm were also more likely to undergo the Narcan administration training. There was also a trend toward increased readiness to change among intervention participants for these 3 behaviors. However, intervention participants did not appear to reduce the frequency of drug use or increase readiness to reduce drug use more than control participants, despite the fact that the majority of intervention participants selected this as the primary goal to focus on after participation in the baseline survey. These results demonstrate that implementing computer-based risk reduction interventions in SSPs may reduce harms related to sharing of injection equipment and prevent overdose deaths.

No significant difference in reducing the frequency of drug use was observed between the intervention and control participants. Multiple interpretations of this finding are plausible. Hep-Net was a single-session, brief intervention. Reducing substance use is likely to require multipronged strategies, including provision of social, psychological, and physical support. Although Hep-Net in isolation did not affect significant changes in this behavior, it may be useful if integrated into other existing programs to more holistically address the complexity of addiction. Furthermore, almost half of the participants did not return for follow-up. It may be that those who did not return for follow-up disproportionately included individuals who were successful in reducing their substance use and therefore did not return to the needle exchange. Increasing the dosage and comprehensiveness of the intervention may also bolster the effect and allow individuals to reduce drug use and reach their recovery goals. For example, implementing booster sessions that expose clients to additional intervention content may strengthen the effect it has on reducing the frequency of drug use. Understanding how interventions may be enhanced to effectively reduce drug use and improve long-term recovery success among SSP clients is greatly needed.

Although CTIs have become increasingly common for facilitating a wide range of health-promoting behaviors, very few studies have examined the effect of a single CTI on multiple risk behaviors among people who inject drugs in SSP or other community-based settings. With regard to CTIs addressing substance abuse, previous studies have instead primarily focused on HIV/AIDS prevention [34,35], perinatal drug use [36,37], or alcohol use disorders [38,39] or were coupled with 
therapist-delivered treatments [40,41]. To our knowledge, only one randomized trial has evaluated the efficacy of a CTI for the adoption of safer injection practices among SSP clients. This study found that IV drug users visiting SSPs who received the CTI were using dirty syringes 0.47 times in less than 1 month after the intervention began compared with those who did not receive the CTI; however, the positive effect was short-lived [42]. This study is the first to implement a single CTI into SSPs to address safe injection practices, substance use reduction, hepatitis $\mathrm{C}$ testing, and overdose prevention simultaneously. Additional research on CTIs for SSP clients is needed because of its potential to address the challenges of resource limitations facing many affected communities.

The transtheoretical model has been used in the development of various substance abuse interventions and has demonstrated success because it accounts for individuals who are not ready to make behavior change or who do not see their behavior as problematic [30]. However, there is limited research on applying the transtheoretical model to promote healthy behaviors specifically among people who inject drugs, who are engaged in prevention services. Prior studies using transtheoretical model-designed interventions to promote behavior change among people who inject drugs have been restricted to increasing condom use and using bleach to clean drug paraphernalia [43-45]. In this study, we found that most people were in the preparation, action, or maintenance stage for all behaviors at baseline. This heightened readiness may have partially limited our ability to detect the statistical significance in this study.

\section{Limitations}

We demonstrate the effects of a brief, digitally delivered tailored intervention designed to reduce HCV risk behaviors among hard-to-reach individuals who inject drugs. Although our study has much to offer, it is not without limitations. Although delivering the intervention through a well-established SSP that holds strong relationships with many members of the targeted population was a major strength of this study, communities that lack such a developed SSP may fail to reach less-engaged clientele. Generalizability may also be limited because individuals utilizing SSPs may choose to prioritize their health and value safe injection practices more strongly than those not engaged in prevention services, as suggested by the high proportion of individuals in the preparation, action, and maintenance stages of behavior change. For this reason, we implemented a social network-based recruitment strategy to engage difficult-to-reach individuals.

Assessments of drug use behaviors were self-reported measures. However, we anticipate that the computerized approach to data collection maximizes privacy and, in turn, mitigates social desirability bias.

Finally, the primary aim of this pilot study was to assess the feasibility of the social network recruitment approach [29]. As such, the sample size may not be sufficiently powered to detect small effect sizes, particularly for subgroup analyses. Further analysis with improved power is needed to improve our understanding of the effectiveness of computer-tailored risk reduction interventions implemented in SSP settings.

\section{Conclusions}

As the opioid epidemic continues to burden rural communities, expanding the delivery of comprehensive prevention services in resource-poor settings is critically important. To be most effective, prevention services should be patient-centered and provide individual, personalized plans for risk reduction that are responsive to their unique preferences, needs, and motivations. Using fast data-driven decision guidelines, CTIs offer the opportunity to deliver individualized care even in settings facing resource limitations. Implementing CTIs in SSP settings is one approach for engaging highly marginalized and underserved populations of people who inject drugs and facilitate the uptake of safe injection practices, decrease opioid overdose deaths, and reduce the transmission of blood-borne infections. Although such interventions may prevent some devastating consequences of injection drug use, additional efforts are needed to help individuals reduce drug use and overcome the power of addiction.

\section{Acknowledgments}

The authors would specifically like to thank the SSP clients who participated in this study as well as the SSP staff, whose established relationships with the SSP clients allowed for the successful Hep-Net implementation and follow-up. This project was supported by the Clinical and Translational Science Award program through the National Institutes of Health-National Center for Advancing Translational Sciences, grants UL1TR000427 and UL1TR002373, and the University of Wisconsin-Madison School of Medicine and Public Health's Wisconsin Partnership Program.

\section{Conflicts of Interest}

None declared.

\section{Multimedia Appendix 1}

CONSORT-eHEALTH checklist (V 1.6.1).

[PDF File (Adobe PDF File), 1629 KB-Multimedia Appendix 1]

\section{References}


1. National Survey on Drug Use and Health: Detailed Tables. Substance Abuse and Mental Health Services Administration. 2018. URL: https://www.samhsa.gov/data/sites/default/files/cbhsq-reports/NSDUHDetailedTabs2017/ NSDUHDetailedTabs2017.pdf [accessed 2020-05-01]

2. Overdose Death Rates. National Institute on Drug Abuse (NIDA). 2018 Jan 24. URL: https://www.drugabuse.gov/ related-topics/trends-statistics/overdose-death-rates [accessed 2020-05-01]

3. Hepatitis C Testing Recommendations. Centers for Disease Control and Prevention. 2015. URL: https://www.cdc.gov/ hepatitis/hcv/index.htm [accessed 2020-05-01]

4. Zibbell JE, Asher AK, Patel RC, Kupronis B, Iqbal K, Ward JW, et al. Increases in acute hepatitis C virus infection related to a growing opioid epidemic and associated injection drug use, United States, 2004 to 2014. Am J Public Health 2018 Mar;108(2):175-181. [doi: 10.2105/AJPH.2017.304132] [Medline: 29267061]

5. Suryaprasad A, White JZ, Xu F, Eichler BA, Hamilton J, Patel A, et al. Emerging epidemic of hepatitis C virus infections among young nonurban persons who inject drugs in the United States, 2006-2012. Clin Infect Dis 2014 Dec 15;59(10):1411-1419. [doi: 10.1093/cid/ciu643] [Medline: 25114031]

6. Zibbell JE, Iqbal K, Patel RC, Suryaprasad A, Sanders KJ, Moore-Moravian L, Centers for Disease ControlPrevention (CDC). Increases in hepatitis $\mathrm{C}$ virus infection related to injection drug use among persons aged $\leq 30$ years - Kentucky, Tennessee, Virginia, and West Virginia, 2006-2012. MMWR Morb Mortal Wkly Rep 2015 May 8;64(17):453-458 [FREE Full text] [Medline: 25950251]

7. Centers for Disease Control and Prevention (CDC). Notes from the field: hepatitis $\mathrm{C}$ virus infections among young adults--rural Wisconsin, 2010. MMWR Morb Mortal Wkly Rep 2012 May 18;61(19):358 [FREE Full text] [Medline: 22592276]

8. Centers for Disease Control and Prevention (CDC). Hepatitis C virus infection among adolescents and young adults:Massachusetts, 2002-2009. MMWR Morb Mortal Wkly Rep 2011 May 6;60(17):537-541 [FREE Full text] [Medline: 21544042]

9. Christian WJ, Hopenhayn C, Christian A, McIntosh D, Koch A. Viral hepatitis and injection drug use in Appalachian Kentucky: a survey of rural health department clients. Public Health Rep 2010;125(1):121-128 [FREE Full text] [doi: 10.1177/003335491012500116] [Medline: 20402204]

10. Use of Enhanced Surveillance for Hepatitis C Virus Infection to Detect a Cluster Among Young Injection-Drug Users --New York, November 2004--April 2007. Centers for Disease Control and Prevention. 2008. URL: https://www.cdc.gov/ mmwr/preview/mmwrhtml/mm5719a3.htm [accessed 2020-05-01]

11. Peters PJ, Pontones P, Hoover KW, Patel MR, Galang RR, Shields J, Indiana HIV Outbreak Investigation Team. HIV infection linked to injection use of oxymorphone in Indiana, 2014-2015. N Engl J Med 2016 Jul 21;375(3):229-239. [doi: 10.1056/NEJMoa1515195] [Medline: 27468059]

12. van Handel MM, Rose CE, Hallisey EJ, Kolling JL, Zibbell JE, Lewis B, et al. County-level vulnerability assessment for rapid dissemination of HIV or HCV infections among persons who inject drugs, United States. J Acquir Immune Defic Syndr 2016 Nov 1;73(3):323-331 [FREE Full text] [doi: 10.1097/QAI.0000000000001098] [Medline: 27763996]

13. Hagan H, Jarlais DC, Friedman SR, Purchase D, Alter MJ. Reduced risk of hepatitis B and hepatitis C among injection drug users in the Tacoma syringe exchange program. Am J Public Health 1995 Dec;85(11):1531-1537. [doi: 10.2105/ajph.85.11.1531] [Medline: 7485666]

14. Iversen J, Wand H, Topp L, Kaldor J, Maher L. Reduction in HCV incidence among injection drug users attending needle and syringe programs in Australia: a linkage study. Am J Public Health 2013 Aug;103(8):1436-1444. [doi:

10.2105/AJPH.2012.301206] [Medline: 23763399]

15. Aspinall E, Nambiar D, Goldberg DJ, Hickman M, Weir A, van Velzen E, et al. Are needle and syringe programmes associated with a reduction in HIV transmission among people who inject drugs: a systematic review and meta-analysis. Int J Epidemiol 2014 Mar;43(1):235-248. [doi: 10.1093/ije/dyt243] [Medline: 24374889]

16. Vlahov D, Junge B. The role of needle exchange programs in HIV prevention. Public Health Rep 1998 Jun;113(Suppl 1):75-80 [FREE Full text] [Medline: 9722812]

17. Kaplan EH. A method for evaluating needle exchange programmes. Stat Med 1994;13(19-20):2179-2187. [doi: 10.1002/sim.4780131923] [Medline: 7846418]

18. des Jarlais DC, Perlis T, Arasteh K, Torian LV, Hagan H, Beatrice S, et al. Reductions in hepatitis C virus and HIV infections among injecting drug users in New York City, 1990-2001. AIDS 2005 Oct;19(Suppl 3):S20-S25. [doi:

10.1097/01.aids.0000192066.86410.8c] [Medline: 16251819]

19. Hagan H, McGough JP, Thiede H, Hopkins S, Duchin J, Alexander E. Reduced injection frequency and increased entry and retention in drug treatment associated with needle-exchange participation in Seattle drug injectors. J Subst Abuse Treat 2000 Oct;19(3):247-252. [doi: 10.1016/s0740-5472(00)00104-5] [Medline: 11027894]

20. Watters JK, Estilo MJ, Clark GL, Lorvick J. Syringe and needle exchange as HIV/AIDS prevention for injection drug users. J Am Med Assoc 1994 Jan 12;271(2):115-120. [Medline: 8264065]

21. Marx MA, Brahmbhatt H, Beilenson P, Brookmeyer RS, Strathdee SA, Alexander C, et al. Impact of needle exchange programs on adolescent perceptions about illicit drug use. AIDS Behav Vol 2001;5(4):379-386 [FREE Full text] [doi: 10.1023/A:1013195108756] 
22. Syringe Exchange Programs --- United States, 2008. Centers for Disease Control and Prevention. 2010. URL: https://www. cdc.gov/mmwr/preview/mmwrhtml/mm5945a4.htm/Syringe-Exchange-Programs-United-States-2008 [accessed 2020-05-01]

23. des Jarlais DC. Harm reduction in the USA: the research perspective and an archive to David Purchase. Harm Reduct J 2017 Jul 26;14(1):51 [FREE Full text] [doi: 10.1186/s12954-017-0178-6] [Medline: 28747189]

24. Rudolph A, Standish K, Amesty S, Crawford N, Stern R, Badillo W, et al. A community-based approach to linking injection drug users with needed services through pharmacies: an evaluation of a pilot intervention in New York City. AIDS Educ Prev 2010 Jul;22(3):238-251 [FREE Full text] [doi: 10.1521/aeap.2010.22.3.238] [Medline: 20528131]

25. Rita O, Regan M, Julita V, Kathrin G. Tailoring Persuasive Health Games to Gamer Type. In: Proceedings of the SIGCHI Conference on Human Factors in Computing Systems. 2013 Presented at: CHI'13; April 27, 2013; Paris, France URL: http:/ leprints.lincoln.ac.uk/id/eprint/13641/1/_ddat02_staffhome_jpartridge_p2467-orji.pdf [doi: 10.1145/2470654.2481341]

26. Orji R, Moffatt K. Persuasive technology for health and wellness: state-of-the-art and emerging trends. Health Informatics J 2018 Mar;24(1):66-91 [FREE Full text] [doi: 10.1177/1460458216650979] [Medline: 27245673]

27. Orji T, Mandryk RL. Developing culturally relevant design guidelines for encouraging healthy eating behavior. Int J Hum Comput Stud 2014 Feb;72(2):207-223 [FREE Full text] [doi: 10.1016/j.ijhcs.2013.08.012]

28. Krebs P, Prochaska JO, Rossi JS. A meta-analysis of computer-tailored interventions for health behavior change. Prev Med 2010;51(3-4):214-221 [FREE Full text] [doi: 10.1016/j.ypmed.2010.06.004] [Medline: 20558196]

29. Westergaard RP, Hull SJ, Merkow A, Stephens LK, Hochstatter KR, Olson-Streed HK, et al. Computerized tailored interventions to enhance prevention and screening for hepatitis $\mathrm{C}$ virus among people who inject drugs: protocol for a randomized pilot study. JMIR Res Protoc 2016 Jan 22;5(1):e15 [FREE Full text] [doi: 10.2196/resprot.4830] [Medline: 26800903]

30. Prochaska JO, Velicer WF. The transtheoretical model of health behavior change. Am J Health Promot 1997;12(1):38-48. [doi: 10.4278/0890-1171-12.1.38] [Medline: 10170434]

31. Prochaska JO, Redding CA, Harlow LL, Rossi JS, Velicer WF. The transtheoretical model of change and HIV prevention: a review. Health Educ Q 1994;21(4):471-486. [doi: 10.1177/109019819402100410] [Medline: 7843978]

32. Richards CM, Sharif F, Eischen S, Thomas J, Wang Q, Guo H, et al. Retention of homeless smokers in the power to quit study. Nicotine Tob Res 2015 Oct;17(9):1104-1111 [FREE Full text] [doi: 10.1093/ntr/ntu210] [Medline: 25301816]

33. Baggett TP, O'Connell JJ, Singer DE, Rigotti NA. The unmet health care needs of homeless adults: a national study. Am J Public Health 2010 Jul;100(7):1326-1333. [doi: 10.2105/AJPH.2009.180109] [Medline: 20466953]

34. Marsch LA, Bickel WK. Efficacy of computer-based HIV/AIDS education for injection drug users. Am J Health Behav 2004;28(4):316-327. [doi: 10.5993/ajhb.28.4.3] [Medline: 15228968]

35. Marsch LA, Grabinski MJ, Bickel WK, Desrosiers A, Guarino H, Muehlbach B, et al. Computer-assisted HIV prevention for youth with substance use disorders. Subst Use Misuse 2011;46(1):46-56 [FREE Full text] [doi:

10.3109/10826084.2011.521088] [Medline: 21190405]

36. Ondersma SJ, Chase SK, Svikis DS, Schuster CR. Computer-based brief motivational intervention for perinatal drug use. J Subst Abuse Treat 2005 Jul;28(4):305-312 [FREE Full text] [doi: 10.1016/j.jsat.2005.02.004] [Medline: 15925264]

37. Ondersma SJ, Svikis DS, Schuster CR. Computer-based brief intervention a randomized trial with postpartum women. Am J Prev Med 2007 Mar;32(3):231-238 [FREE Full text] [doi: 10.1016/j.amepre.2006.11.003] [Medline: 17236741]

38. Hester RK, Delaney HD. Behavioral self-control program for windows: results of a controlled clinical trial. J Consult Clin Psychol 1997 Aug;65(4):686-693. [doi: 10.1037//0022-006x.65.4.686] [Medline: 9256570]

39. Hester RK, Squires DD, Delaney HD. The Drinker's check-up: 12-month outcomes of a controlled clinical trial of a stand-alone software program for problem drinkers. J Subst Abuse Treat 2005 Mar;28(2):159-169. [doi: 10.1016/j.jsat.2004.12.002] [Medline: 15780546]

40. Bickel WK, Marsch LA, Buchhalter AR, Badger GJ. Computerized behavior therapy for opioid-dependent outpatients: a randomized controlled trial. Exp Clin Psychopharmacol 2008 May;16(2):132-143 [FREE Full text] [doi: 10.1037/1064-1297.16.2.132] [Medline: 18489017]

41. Carroll KM, Ball SA, Martino S, Nich C, Babuscio TA, Nuro KF, et al. Computer-assisted delivery of cognitive-behavioral therapy for addiction: a randomized trial of CBT4CBT. Am J Psychiatry 2008 Jul;165(7):881-888 [FREE Full text] [doi: 10.1176/appi.ajp.2008.07111835] [Medline: 18450927]

42. Gagnon H, Godin G, Alary M, Bruneau J, Otis J. A randomized trial to evaluate the efficacy of a computer-tailored intervention to promote safer injection practices among drug users. AIDS Behav 2010 Jul;14(3):538-548. [doi: 10.1007/s10461-009-9651-x] [Medline: 20033276]

43. Jamner MS, Wolitski RJ, Corby NH. Impact of a longitudinal community HIV intervention targeting injecting drug users' stage of change for condom and bleach use. Am J Health Promot 1997;12(1):15-24. [doi: 10.4278/0890-1171-12.1.15] [Medline: 10170430]

44. Bowen AM, Trotter R. HIV risk in intravenous drug users and crack cocaine smokers: predicting stage of change for condom usep. J Consult Clin Psychol 1995 May;63(2):238-248. [doi: 10.1037//0022-006x.63.2.238] [Medline: 7751484]

45. Patten S, Vollman A, Thurston W. The utility of the transtheoretical model of behavior change for HIV risk reduction in injection drug users. J Assoc Nurses AIDS Care 2000;11(1):57-66. [doi: 10.1016/S1055-3290(06)60422-6] [Medline: 10670007] 


\section{Abbreviations}

CTI: computer-tailored intervention

HCV: hepatitis $\mathrm{C}$ virus

RCT: randomized controlled trial

SSP: syringe service program

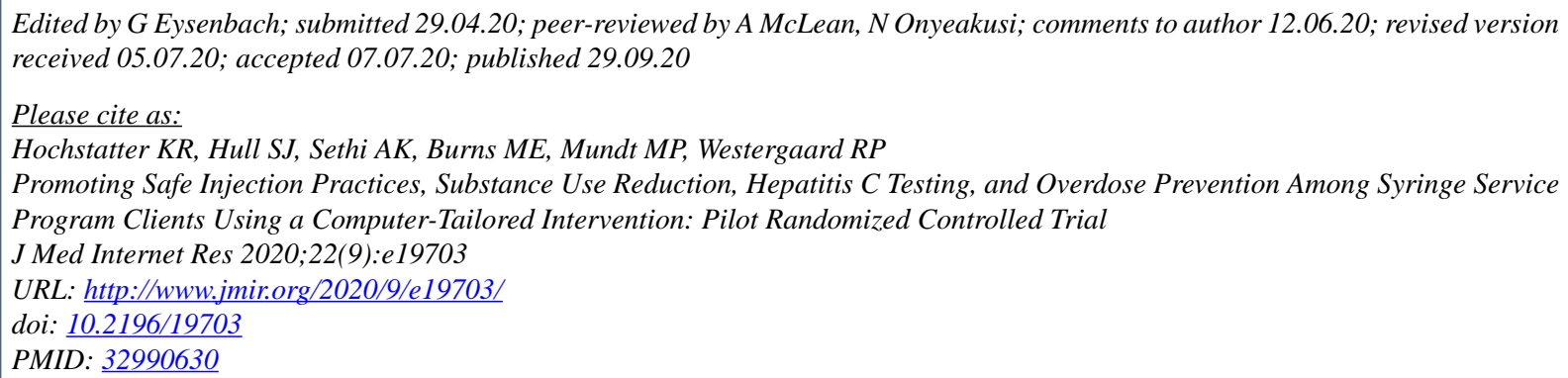

CKarli R Hochstatter, Shawnika J Hull, Ajay K Sethi, Marguerite E Burns, Marlon P Mundt, Ryan P Westergaard. Originally published in the Journal of Medical Internet Research (http://www.jmir.org), 29.09.2020. This is an open-access article distributed under the terms of the Creative Commons Attribution License (https://creativecommons.org/licenses/by/4.0/), which permits unrestricted use, distribution, and reproduction in any medium, provided the original work, first published in the Journal of Medical Internet Research, is properly cited. The complete bibliographic information, a link to the original publication on http://www.jmir.org/, as well as this copyright and license information must be included. 